\title{
O036. Cocaine and headache: a 2-year follow-up study in chronic cocaine users and literature review
}

\author{
Luisa Fofi ${ }^{1}$, Valerio Orlandi ${ }^{2}$, Nicola Vanacore ${ }^{3}$, Maria C Mizzoni ${ }^{2}$, Alba Rosa ${ }^{2}$, Cinzia Aurilia ${ }^{1}$, Gabriella Egeo ${ }^{1}$, \\ Pietro Casella ${ }^{2}$, Piero Barbanti ${ }^{*}$
}

From Abstracts from the 1st Joint ANIRCEF-SISC Congress

Rome, Italy. 29-31 October 2015

As many as $14-21$ million people worldwide $(0.3-0.5 \%$ of the population, aged 15-65 years) use cocaine [1]. In Europe, cocaine consumption has shown a 2- to 3-fold increase during the last 2 decades [2,3]; in Italy, lifetime cocaine experience among adults corresponds to $6.6 \%$ [4]. Cocaine use and headache share some common characteristics: present heavy global burden, prevail among young individuals, cause more severe consequences in females, may lead to emergency department access and progress to chronification. The study of headache in chronic cocaine users (CCU) is of interest also from a pathophysiological point of view, given that chronic cocaine use causes decreased dopamine and serotonin synaptic levels, a typical migraine biochemical feature ("empty neuron" condition) [5,6]. In a previous study we encouraged clinicians to carry out a more in-depth investigation on cocaine use in all headache suffers, especially those with migraine, as headache occurs in a very high proportion of CCU (90\%), mostly showing migraine or migraine-like characteristics, while cocaine-induced headache, as classified by the ICHD criteria [7], seems exceedingly rare (2.2\%). Moreover, we pointed out that $\mathrm{CCU}$ sometimes use cocaine as an acute remedy for the headache attack, even though improvement occurs very rarely (17.2\% of cases) [8]. Recently, it has been described that patients with intractable cluster headache who tried cocaine, being dissatisfied with conventional treatments in terms of efficacy and/or tolerability, referred a full or partial improvement in $30.8 \%$ of cases [9]. The present study was aimed to evaluate the modification of the

\footnotetext{
* Correspondence: piero.barbanti@sanraffaele.it

'Headache and Pain Unit, Department of Neurological, Motor and Sensorial Sciences, IRCCS San Raffaele Pisana, Rome, Italy

Full list of author information is available at the end of the article
}

clinical characteristics of headache in CCU after a 2-year follow-up period. We contacted by phone the 80 patients previously enrolled [8] attending the Cocaine Addiction Service of the Drug Addiction Service, 20th District, Rome. Of these 80 patients, 60 (still followed by the Drug Addiction Service) were enrolled and interviewed by the same physicians of the previous study. We studied the modifications of headache pattern and characteristics relative to their actual cocaine consumption in CCU patients previously subdivided into 3 groups: neither lifetime nor current headache (group 0); lifetime and current headache (group 1); and de novo headache, i.e. individuals in whom headache developed only after cocaine use began (group 2). The correlation between headache and cocaine is controversial and still understimated.

Written informed consent to publish was obtained from the patient(s).

Conflict of interest

None.

\section{Aknowledgment}

No funding.

\section{Authors' details}

'Headache and Pain Unit, Department of Neurological, Motor and Sensorial Sciences, IRCCS San Raffaele Pisana, Rome, Italy. ${ }^{2}$ Drug Addiction Service, 20th District, UOS Municipio 17, ASL RME, Rome, Italy. ${ }^{3}$ National Centre of Epidemiology, Surveillance and Health Promotion, National Institute of Health, Rome, Italy.

\section{Published: 28 September 2015}

\section{References}

1. Pomara C, Cassano T, D'Errico S, Bello S, Romano AD, Riezzo I, Serviddio G: Data available on the extent of cocaine use and dependence: biochemistry, pharmacologic effects and global burden of disease of cocaine abusers. Curr Med Chem 2012, 19(33):5647-5657. 
2. Karila L, Zarmdini R, Petit A, Lafaye G, Lowenstein W, Reynaud M: Cocaine addiction: current data for the clinician. Presse Med 2014, 43(1):9-17.

3. Mena G, Giraudon I, Álvarez E, Corkery JM, Matias J, Grasaasen K, et al: Cocaine-related health emergencies in Europe: a review of sources of information, trends and implications for service development. Eur Addict Res 2013, 19(2):74-81.

4. European Monitoring Centre for Drugs and Drugs Addiction (EMCDDA) Annual Report 2009: the state of the drugs problem in Europe. Lisbon: EMCDDA; http://www.emcdda.europa.eu/publications/annual-report/2009 (Accessed May 18, 2012).

5. Nestler EJ: The neurobiology of cocaine addiction. Sci Pract Perspect 2005, 3(1):4-10.

6. Sicuteri F, Fanciullacci M, Michelacci S: Decentralization supersensitivity in headache and central panalgesia. Res Clin Stud Headache 1978, 6:19-33.

7. Headache Classification Committee of the International Headache Society (IHS): The International Classification of Headache Disorders, 3rd edition (beta version) Headache Classification Committee of the International Headache Society (IHS). Cephalalgia 2013, 33(9):629-808.

8. Fofi L, Orlandi V, Vanacore N, Mizzoni MC, Rosa A, Aurilia C, et al: Headache in chronic cocaine users: A cross-sectional study. Cephalalgia 2014, 34(9):671-678.

9. Di Lorenzo C, Coppola G, Di Lorenzo G, Bracaglia M, Rossi P, Pierelli F: The use of illicit drugs as self-medication in the treatment of cluster headache: Results from an Italian online survey. Cephalalgia 2015, pii: 0333102415583145.

doi:10.1186/1129-2377-16-S1-A167

Cite this article as: Fofi et al.: O036. Cocaine and headache: a 2-year

follow-up study in chronic cocaine users and literature review. The Journal of Headache and Pain 2015 16(Suppl 1):A167.

\section{Submit your manuscript to a SpringerOpen ${ }^{\odot}$ journal and benefit from:}

- Convenient online submission

- Rigorous peer review

- Immediate publication on acceptance

- Open access: articles freely available online

- High visibility within the field

- Retaining the copyright to your article 